\title{
Author/Subject Indexes Vol. 39, No. 3, 1996
}

Aoki,H. 140

Kühn,J. 139

Arakawa, Y. 140

Landini, M.P. 193

Bergström, T. 176

Laufs, R. 204

Bruggeman, C.A. 213

Lazzarotto, T. 193

Dal Monte, P. 193

Manservigi, R. 185

Dam-Mieras, M.C.E. van 213

Matsuoka, M. 158

Dörries, K. 165

Pfister,H. 145

Etoh,K. 158

Revello, M.G. 185

Hino,O. 140

Ripalti,A. 193

Kajino,K. 140

Schäfer,P. 204

Takatsuki,K. 158 Takemoto, S. 158 Tamiya, S. 158 Trybala,E. 176 Vossen, R.C.R.M. 213

Wieland,U. 145 Yamaguchi, K. 158 Yamamoto, T. 140

Subject Index Vol. 39, No. 3,1996

Adult T cell leukemia 158 AIDS 193 Antigenemia 204 Antiviral therapy 204 BKV 165

Cervical cancer 145 CMV latency 213 Competitive PCR 204 Congenital infection 204 Diagnosis

140 GB hepatitis virus 140 Glycoprotein C 176 Hepatitis C virus 140

- - RNA 140

G virus 140

Herpes simplex encephalitis 185

- virus 176

- -, glycoproteins 185

HTLV-I 158

- $\quad$ proviralDNA 158

Human cytomegalovirus 193,204

- papilloma viruses 145

Hybridization assays 145

Immunoblotting 176

Immunocompromised patients 204

Immunocytochemistry 145 
Inflammatory response 213

Inverse PCR 158

JCV 165

Monoclonal antibodies, mapping 176

Newborns 193

NF- $\kappa B$ activation 213

Persistent infection 165

Polymerase chain reaction 145,185

Polyomavirus 165

pp65 antigen 204

Pregnant women 193

Prenatal diagnosis 193

Progressive multifocal leukoencephalo-

pathy 165 Renal transplant recipients 204 Restenosis 213

Serology, human papilloma virus 145 Smooth muscle cell proliferation 213 Transplant recipients 193 Transplant-associated arteriosclerosis 213 Type-specific serology 176 Vascular cell activation 213 Viral diagnosis 193 Virus-host interaction 165 